\title{
Boicottare - boicottaggio
}

\section{Domenico Proietti}

PUBBLICATO: 22 OTTOBRE 2019

\section{Quesito:}

Alcuni lettori ci chiedono "una chiara definizione della parola boicottare" anche in rapporto al significato dell'inglese boycott; altre domande vertono su boicottaggio.

\section{Boicottare - boicottaggio}

P er rispondere ai diversi quesiti pervenuti sul significato, in inglese e in italiano, del verbo boicottare, sui suoi usi estensivi e sulla flessione al plurale del derivato boicottaggio, è bene partire dall'origine del vocabolo e dalla sua accezione primaria. È un caso tipico di quel processo di formazione delle parole che, riferendoci al titolo di una fondamentale ricerca di Bruno Migliorini (I908, rist. con aggiunte nel I968), possiamo indicare con l'espressione Dal nome proprio al nome comune. Il verbo inglese to boycott (da cui derivano il francese boycotter e l'italiano boicottare), infatti, è stato coniato sul cognome del capitano inglese Charles C. Boycott (I832-I897), amministratore del latifondo di Lord Erne, nella contea di Mayo (Irlanda occidentale). Per protestare contro le inaccettabili condizioni con cui il capitano Boycott gestiva i rapporti con braccianti e fittavoli, la Irish Land League (Lega irlandese dei lavoratori della terra) organizzò nel corso del i88o una campagna non violenta con l'obiettivo di isolarlo e indurlo alla trattativa: non solo i contadini ma l'intera popolazione della contea di Mayo interruppero i rapporti e i servizi con Boycott e la sua amministrazione. Il fatto ebbe forte eco nell'opinione pubblica inglese, anche perché lo stesso Boycott denunciò la situazione con una serie di lettere-resoconti al "Times". Lintervento del governo inglese (che nel novembre dello stesso anno inviò un contingente militare nella contea) non impedi il licenziamento di Boycott, che dovette lasciare l'Irlanda nel dicembre i880.

Il verbo to boycott e derivati figurano già nel primo volume (I888) dell'Oxford English Dictionary, dove, curiosamente, nella parte etimologica si specifica che il vocabolo è formato su "the name of Capt. Boycott, an Irish landlord, who was the original victim of the treatment descrive" ed e definito "To combine in refusing to hold relations of any kind, social or commercial, public or private, with (a neighbour), on account of political or other differences, so as to punish him for the position he has taken up, or coerce him into abandoning it" ['Accordarsi nel rifiutare relazioni di ogni tipo, sociali o commerciali, pubbliche o private, con (un vicino), a causa di differenze politiche o di altro genere, cosi da punirlo per la posizione che ha assunto, o costringerlo ad abbandonarla', ndr].

Della voce si danno anche diversi derivati (tra cui boycotting, 'boicottaggio'; boycotter 'boicottatore', ecc.), si rileva che essa "was speedly adopted by the newspapers" e che pertanto è "generally written without an initial capital letter". Si riportano esempi da giornali inglesi della fine del I880, si osserva che to boycott e derivati si sono presto diffusi "in nearly every European language" e si citano corrispettivi in francese, olandese, tedesco e russo, ma non in italiano. Eppure, le prime attestazioni italiane, nella grafia boycottare, risalgono al I88I-82 (cfr. A.L. Messeri, Anglicismi nel linguaggio politico italiano nel '7oo e nell'8oo, in "Lingua nostra", XVIII, I957, pp. I00-I08, a pp. I02-I03), per es.: "gl'inglesi sono furibondi e fanno la loro dimostrazione a favore di quel Boycott che fu rovina ad onta dei soldati mandati a proteggere i suoi raccolti, cio che ha introdotto un nuovo vocabolo, boycottare, nella lingua inglese" (Rivista politica, in "L'Illustrazione Italiana", 2 gennaio I88I, p. 2). Tra i derivati in 
un primo tempo prevalse la forma boicottamento (attestata dal I887), il che ha fatto pensare che "il verbo [boicottare] non ci è pervenuto attraverso il francese" (G. Rando, Dizionario degli anglicismi nellitaliano postunitario, Firenze, Olschki, 1987, p.I7). In realtà, occorrenze molto precoci della variante boicottaggio (per es. "e se il boicottare ed il boicottaggio, che già si videro nelle gazzette, s'introducessero nella lingua, gioverebbe a loro intelligenza il ricordare quale fu il caso del Capitano Boycott, che a tali voci dette suo malgrado occasione", Salvatore Bongi, recensione, datata 8 aprile i882, del Dizionario del linguaggio italiano storico ed amministrativo (I88I) di Giulio Rezasco, in "Archivio storico italiano", 4. s., IX, I882, pp. 383-395, a p. 388) e il fatto che le prime attestazioni del francese boycotter e derivati risalgono alla fine del I88o quantomeno spingono a riaprire la questione (cfr., per es.: "A Limerick [...] le Boycottage va son train. Les gens Boycottés quittent leurs fermes où ils ne peuvent plus se nourrir" ['A Limerick [...] il boicottaggio va avanti. Le persone boicottate lasciano le loro fattorie dove non trovano più sostentamento', ndr], "Le Figaro", I5 dicembre i88o, p. 4). Si tratterebbe, dunque, di uno dei tanti esempi di termini inglesi con suffisso -ing (lynching, 'linciaggio'; monitoring 'monitoraggio', ecc.) adattati in italiano con il suffisso -aggio (il plurale è, regolarmente, boicottaggi) per intermediazione morfologica del francese (cfr. anche R. Bombi, Anglicismi come banco di prova dellinterferenza linguistica, in Italiano e inglese a confronto, a cura di A.V. Sullam Calimani, Firenze, Cesati, 2003, pp. 99-I23, a p. II5).

In ogni caso, in italiano (cosi come nei corrispettivi in inglese e francese) il significato originario di boicottare è quello di "colpire con un'azione più o meno concordata tendente a isolare individui, enti o prodotti da un consorzio o da un mercato, a fini di lotta politica, economica o commerciale". In senso estensivo, può essere utilizzato per indicare azioni di isolamento e quindi riprovazione sulla spinta di motivazioni etiche o morali: boicottare un film, uno spettacolo, una manifestazione, ecc. Non si tratta, dunque, di "azioni attive" rivolte a "causa[re] danni ad altri" (come ipotizza la richiedente di Nervesa della Battaglia) ma iniziative di reazione, rappresaglia, ecc. in cui il danno che si intende arrecare ha il fine di colpire, impedire o punire azioni o comportamenti ritenuti deleteri, inopportuni, ingiusti.

Non rientra, invece, nei valori semantici del verbo boicottare l'espressione (richiamata nel quesito di un richiedente di Como) "sei boicottato per domani a venire con me", che dovrebbe essere invece formulata "sei precettato a venire con me", con riuso familiare e scherzoso del verbo giuridicoamministrativo precettare.

\section{Cita come:}

Domenico Proietti, Boicottare - boicottaggio , "Italiano digitale", 2019, XI, 2019/4 (ottobredicembre)

DOI: $10.35948 / 2532-9006 / 2020.3259$

Copyright 2019 Accademia della Crusca

Pubblicato con licenza creative commons CC BY-NC-ND 